\title{
Mesocrystal MnO Cubes as Anode for Li-ion Capacitors
}

Chaofeng Liu ${ }^{\S}$, Changkun Zhang ${ }^{\S}$, Huanqiao Song ${ }^{\S}$, Cuiping Zhang ${ }^{\S}$, Yaguang Liu ${ }^{\S}$, Xihui $\mathrm{Nan}^{\S}$, Guozhong $\mathrm{Cao}^{\S \dagger *}$

${ }^{\S}$ Beijing Institute of Nanoenergy and Nanosystems, Chinese Academy of Sciences, Beijing, 100083, China

${ }^{\dagger}$ Department of Materials Science and Engineering, University of Washington, Seattle, Washington, 98195, USA

Keywords: Li-ion capacitor, mesocrystal MnO cubes, homoepitaxial aggregation, anode, cationic vacancies

\begin{abstract}
Mesocrystal $\mathrm{MnO}$ cubes consisted of nanocrystals $(\sim 16 \mathrm{~nm})$ with percolated nanopores $(\sim 10.5 \mathrm{~nm})$ and a porosity of $45 \%$ were synthesized through polyvinyl alcohol (PVA) assisted hydrothermal growth and homoepitaxial aggregation. The resulting $\mathrm{MnO}$ crystal makes up of appreciable amount of $\mathrm{Mn}^{3+}, \sim 11.8 \%$, ascribed to incomplete reduction during the hydrothermal growth, and the presence of such an appreciable amount of $\mathrm{Mn}^{3+}$ is thought to lead to the enhancement of $\mathrm{Li}$ ion diffusion coefficient from $6.96 \times 10^{-14} \mathrm{~cm}^{2} / \mathrm{s}$ to $3.33 \times 10^{-13} \mathrm{~cm}^{2} / \mathrm{s}$. Carbon coating derived from polyvinyl alcohol and homoepitaxial connection of nanocrystals provides excellent charge and mass transfer pathways. Such mesocrystal $\mathrm{MnO}$ cubes enhanced the contact of electrolyte and electrode materials, at the same time the active nanocrystals with trivalent manganese ions and cationic vacancies would promote the conversion
\end{abstract}


reaction for lithium-ion insertion and extraction, leading to a high capacity of 637 $\mathrm{mAh} / \mathrm{g}$ at $100 \mathrm{~mA} / \mathrm{g}$ in a relatively smaller voltage range of $0.05-2.50 \mathrm{~V}$, as compared with a voltage window of $0.01-3 \mathrm{~V}$ used by other research groups. The high voltage (4V) Li-ion capacitor, a full cell with mesocrystal $\mathrm{MnO}$ cubes as anode and activated carbon as cathode, demonstrated excellent cycling performance with the degradation rate of $0.002 \%$ per cycle, and the achieved maximum energy in full capacitor reached $227 \mathrm{Wh} \mathrm{kg}^{-1}$ that calculated on the total weight of the active materials in both electrodes.

\section{Introduction}

Energy storage devices owned both high energy and power density have a huge market potential for the rapid development of portable electronic apparatus, electric vehicles and smart stationary grid as well as for renewable energy ${ }^{[1,2]}$. It is the holy-grail in the field of energy storage technology to search and develop high capacity electrode materials with wide operating voltage window and rapid charge/discharge kinetics ${ }^{[3-5]}$. Combining the high energy density of Li-ion batteries and high power density of supercapacitors provides an alternate approach to satisfy the demand for both high energy and power density devices ${ }^{[6]}$. Batteries offer high energy density but suffer from relatively low power density, while supercapacitors possess high power density with limited energy density ${ }^{[3,7]}$. Li-ion batteries store chemical potential and convert it to electricity through electrode-electrolyte interface redox reactions accompanied with solid state charge and mass diffusion through 
electrodes, whereas electric double layer capacitors (also known as supercapacitors) rely on the formation of electric double layers at the interface between electrode and electrolyte without solid state mass transport through electrode ${ }^{[7]}$. Li-ion capacitors integrate the merits of high specific energy of Li-ion batteries and high power density of electric double layer capacitors (EDLCs) ${ }^{[6,8]}$. Besides, with a given capacity, the wide operating voltage window of Li-ion electrolytes endows high energy density, which is directly proportional to the operating voltage squared. There are two ways to enhance the energy density of Li-ion capacitors. One is to develop or explore redox electrode materials with high capacity, and the other is to increase the working voltage of the capacitors. In Li-ion capacitors, the working voltage is largely determined by the nature of electrolyte. Aqueous electrolyte limits the working voltage of $\sim 1 \mathrm{~V}$, to avoid the water electrolysis ${ }^{[9]}$. Organic electrolytes, such as tetraethylammonium tetrafluoroborate (TEATFB $)^{[10]}, \mathrm{LiFP}_{6}$ or $\mathrm{LiClO}_{4}$ organic solution ${ }^{[11]}$ and ionic liquids $\left(\right.$ ILs ${ }^{[12]}$, have wide voltage windows, which are dependent on the energy separation of the lowest unoccupied molecular orbital (LUMO) and the highest occupied molecular orbital (HOMO) of the electrolyte. Among various Li-ion electrolytes, $\mathrm{LiPF}_{6}$ electrolyte possess a tunable working voltage of $0-6 \mathrm{~V}$ through the introduction of additives or change solvent compositions ${ }^{[13,14]}$. The electrochemical potential of cathodes $\left(\mu_{C}\right)$ and anodes $\left(\mu_{A}\right)$ should be matched with the HOMO and LUMO of electrolyte to avoid the decomposition reaction occurred between electrolyte and electrodes $^{[15]}$, so choosing suitable electrode materials for Li-ion electrolytes is an important consideration in the design and fabricating of Li-ion capacitors. 
Manganese oxides are promising electrode materials to develop high performance $\mathrm{Li}$ ion batteries ${ }^{[16]}$ or supercapacitors ${ }^{[17,18]}$ due to their high theoretical capacity, abundance in earth, environmental benign and low cost. MnO used as an anode offers two advantages. First, its discharge voltage plateau at $0.5 \mathrm{~V}$ coincides with that of the commercial graphite, this voltage plateau closes to the LUMO of electrolyte without side reactions and neither at the cost of sacrificing the voltage window. The second is that its theoretical capacity exceeds $760 \mathrm{mAh} / \mathrm{g}$, more than twice of the commercial graphite $(372 \mathrm{mAh} / \mathrm{g})$, based on the conversion reaction in the charge/discharge process. In fact, the measured capacities of $\mathrm{MnO}$ could be higher than the theoretical value due to the strong interphase interaction ${ }^{[19,20]}$. At the same time, designing and controlling the microstructures of electrodes can promote the kinetic nature for rapid redox reaction during energy storage or release ${ }^{[3,21,22]}$. Therefore, carbon coated nanostructured $\mathrm{MnO}$ could be developed as a promising candidate for $\mathrm{Li}$ ion batteries or capacitors.

In this work, mesocrystal $\mathrm{MnO}$ cubes were synthesized using hydrothermal growth and used as an anode to build a high voltage Li-ion capacitor with activated carbon as a cathode. The micrometer-sized mesocrystal $\mathrm{MnO}$ cubes consisting of numerous homoepitaxially aggregated nanocrystals with percolated pores were annealed at $500^{\circ} \mathrm{C}$ in $\mathrm{Ar}$ for $2 \mathrm{~h}$; polymer additives presented in the precursor solution for the hydrothermal growth were pyrolyzed and converted to a thin carbon coating on the 
surface of $\mathrm{MnO}$ nanocrystal not aggregated with other nanocrystals. Activated carbon with a specific surface area of $1800 \mathrm{~m}^{2} / \mathrm{g}$ was chosen as the cathode in this work. Mesocrystal $\mathrm{MnO}$ cubes were investigated by means of X-ray diffractometry (XRD), scanning electron microscopy (SEM), high resolution transmission electron microscopy (HRTEM), Raman spectrum and nitrogen sorption analysis. The charge/discharge and cycling performance of both half and full cells of Li-ion capacitors were characterized. The formation mechanism of mesocrystal $\mathrm{MnO}$ cubes and the relationship between the $\mathrm{MnO}$ anode and the $\mathrm{Li}$-ion capacitor performance have been elaborated.

\section{Experimental}

\section{Synthesis of Mesoporous Single-Crystal MnO Cubic Particles}

3.0 g PVA was dissolved into $30 \mathrm{ml}$ DI water with heating at $90{ }^{\circ} \mathrm{C}$ to form transparent solution. $3.75 \mathrm{mmol} \mathrm{KMnO}_{4}$ and $1.25 \mathrm{mmol} \mathrm{MnCl}_{2}$ were dissolved into 30 and $10 \mathrm{ml}$ DI water, respectively. The PVA solution was added to $\mathrm{KMnO}_{4}$ solution under magnetic stirring seriously with $30 \mathrm{~min}$, then added $\mathrm{MnCl}_{2}$ solution into the mixture and stirred with 30min under same conditions. The mixture was transferred into a $100 \mathrm{ml}$ Teflon lined stainless steel and treated at $180{ }^{\circ} \mathrm{C}$ with $30 \mathrm{~min}$. The product was washed and centrifugated by DI water several times and dried at $60{ }^{\circ} \mathrm{C}$ in an oven. At last, the obtained precursor was calcined at $500{ }^{\circ} \mathrm{C}$ with $2 \mathrm{~h}$ immersed into $\mathrm{Ar}$ atmosphere, the heating rate was $5{ }^{\circ} \mathrm{C} / \mathrm{min}$ and cooling is under nature.

\section{Structural Characterization}


The crystalline structure and microstructure of sample were conducted on a Marcogroup diffractometer (MXP21 VAHF) with a $\mathrm{Cu}-\mathrm{K} \alpha$ radiation source $(\lambda=1.54056 \AA)$ and a scanning electron microscope (SEM, HITACHI SU8200), respectively. The lattice image was observed through high resolution transmission microscopy (HRTEM, FEI/Tecnai G2 F20 S-TWIN TMP) with an accelerating voltage of $200 \mathrm{KV}$. Raman spectrum was collected at $0.65 \mathrm{~cm}^{-1}$ resolution with a Horiba JOBIN YVON Raman system (LabRAM HR Evolution) using an argon ion laser $(532 \mathrm{~nm})$ as the excitation source. The total surface area was investigated using nitrogen sorption analyses via Micromeritics surface area and porosity analyzer (ASAP $2020 \mathrm{HD} 88$, USA). The degas condition was set to $250{ }^{\circ} \mathrm{C}$ with $4 \mathrm{~h}$ under vacuum of $500 \mu \mathrm{mHg}(\sim 0.67$ mbar $)$, all adsorption-desorption measurements were conducted at liquid nitrogen temperature and the Barrett-Joyner-Halenda (BJH) method was adopted to calculate the mesopore surface area, pore volume and pore diameter. TGA/DTA instrument (Mettler-Toledo STAR system, TGA/SDTA) was used to study the content of carbon with a flowing oxygen of $50 \mathrm{ml} / \mathrm{min}$. The electrical conductivity of samples was measured using a direct current four probe technique with a pressure of $4 \mathrm{MPa}$.

\section{Capacitor Fabrication and Electrochemical Characterization}

The electrochemical performances were investigated using 2032 coin cells. To prepare the working electrode, the slurry contained a mixture of $\mathrm{MnO}-\mathrm{C}$, carbon black and poly-(vinyl difluoride) (PVDF) at a weight ratio of 80:10:10 was bladed on a $\mathrm{Cu}$ foil 
and then subjected to thermal treatment at $120^{\circ} \mathrm{C}$ with $12 \mathrm{~h}$ in vacuum. The mass loading of the active material on each electrode disk was $2.0-3.0 \mathrm{mg} \mathrm{cm}^{-2}$. The electrolyte was $1 \mathrm{M} \mathrm{LiPF}_{6}$ in a 1:1:1 (vol \%) mixture of ethylene carbonate, dimethyl carbonate and diethyl carbonate, and a polypropylene film (Celgard 2400) was used as the separator. $\mathrm{Li}$ ion capacitors were fabricated in which commercial activated carbon was employed as cathodes and $\mathrm{MnO}-\mathrm{C}$ electrodes as anodes. To avoid the prethiation on $\mathrm{MnO}$, a separator packaged porous lithium metal foil $(0.3 \mathrm{~mm})$ was positioned between the cathode and anode to provide an abundant $\mathrm{Li}$ sources in electrochemical reaction. The fabrication of cathodes are similar with anodes but on an Al foil. Half cells were also assembled and lithium foil was used as the counter electrode for investigating the electrochemical properties of anode materials. All cells were assembled in an argon-filled glovebox in which both the content of oxygen and water are below $0.5 \mathrm{ppm}$. The contrasting samples of Microsized $\mathrm{MnO}$ and $\mathrm{AC}$ were also fabricated as the steps above.

Galvanostatic charge-discharge tests of all cells were carried out on a Land CT2001A system (Wuhan, China) with various current densities. The operating voltage window for $\mathrm{MnO}-\mathrm{C}$, activated carbon half cells and $\mathrm{Li}$ ion capacitors are $0.05-2.5 \mathrm{~V}\left(v s . \mathrm{Li} / \mathrm{Li}^{+}\right)$, 2.0-4.5V (vs. $\left.\mathrm{Li} / \mathrm{Li}^{+}\right)$and $0.1-4.0 \mathrm{~V} \quad(\mathrm{MnO}-\mathrm{C} / / \mathrm{AC})$, respectively. Cyclic voltammograms (CVs) were conducted on a Solartron SI 1287 at the scanning rate of $0.1 \mathrm{mV} / \mathrm{s}$ for characterizing the redox reaction of electrode materials in the process of charge/discharge. Electrochemical impedance spectroscopy (EIS) were performed 
using the Solartron 1287A in conjunction with a Solartron 1260A impedance analyzer over the frequency range from $100 \mathrm{kHz}$ to $0.1 \mathrm{~Hz}$ and the $\mathrm{AC}$ amplitude was $10.0 \mathrm{mV}$. The current densities for the half cells were calculated on the mass of active materials of electrodes and $\mathrm{Li}$ ion capacitors were determined based on total mass of active materials on both electrodes. All electrochemical measurements were carried out at room temperature. The specific energy and specific power values of Li ion capacitors were calculated as follows:

$$
\begin{gathered}
P=I \times \Delta V / m \\
E=P \times t / 3600 \\
\Delta V=V_{\text {max }}-V_{\text {min }}
\end{gathered}
$$

where $I$ is the discharge current $(\mathrm{A} / \mathrm{g})$ and $t$ is the discharge time (s), $m$ is the total active mass on both electrodes $(\mathrm{Kg}), V_{\max }$ is the potential at the beginning of discharge after the IR drop, and $V_{\min }$ is the potential at the end of discharge.

\section{Results and discussion}

Figure 1a shows the SEM image of single mesocrystal MnO cube. The cube consists of numerous nanocrystals of $15 \mathrm{~nm}$ (the inset in Figure 1a and Figure S1a), and such cube has uniform size of $1 \mu \mathrm{m}$ in the sample (Figure $\mathrm{S} 1 \mathrm{~b}$ ). The apparent lattice fringes with inter-planar spacing of $2.57 \AA$ observed clearly in the HRTEM, are in good accord with the planar distance between (111) planes of $\mathrm{MnO}$ (Figure 1b) and a thin carbon coated on the surface was marked with the double green dash lines. The carbon coating originated from the pyrolysis of polyvinyl alcohol (PVA) that was 
added during the synthesis of $\mathrm{MnO}$ as a growth inhibiting agent to control the size of nanocrystals $^{[23,24]}$. Raman spectrum (Figure 1c) demonstrates the characteristic peaks of carbon; the intensity ratio between the $\mathrm{G}$ band at $1587 \mathrm{~cm}^{-1}$ and the $\mathrm{D}$ band at 1350 $\mathrm{cm}^{-1}\left(\mathrm{I}_{\mathrm{D}} / \mathrm{I}_{\mathrm{G}}\right)$ approximates to 0.91 that indicates the carbon coating has a good degree of graphitization ${ }^{[25,26]}$. This agrees with the XRD result shown in Figure 1d where a broad peak at $23^{\circ}$ is in accord with the characteristic peak (002) of graphite ${ }^{[27]}$. Except the G (002) peak, all other XRD peaks can be well indexed to MnO (space group Fm-3m (225), JCPDS NO.07-0230), which possesses a simple cubic structure as shown in the inset in Figure 1d. From the XRD peak (220), the average size of the $\mathrm{MnO}$ nanocrystals was calculated to be $\sim 16 \mathrm{~nm}$ using Scherer equation, which agrees well with the SEM results. Figure 1e displays the nitrogen sorption isotherm, from which Brunauer-Emmett-Teller (BET) surface area of $74.3 \mathrm{~m}^{2} / \mathrm{g}$ and peak pore size of $\sim 10.5 \mathrm{~nm}$ were obtained, and similarly mesopore volume and porosity were found to be $0.152 \mathrm{~cm}^{3} / \mathrm{g}$ and $45 \%$, respectively. Carbon content of $\sim 11.7 \mathrm{wt} \%$ in $\mathrm{MnO}-\mathrm{C}$ can be calculated using the BET surface area and the thickness of carbon coating $(\sim 0.7 \mathrm{~nm}$ observed from HRTEM), which is approximately $30 \%$ greater than the result of 9.01wt \% obtained from DSC/TG analyses (shown in Figure S2). The difference in carbon content between calculated and measured results is ascribed to the calculation based on a continuous and compact carbon coating, while the actual carbon coating might contain a fraction of pores. Assuming all nanocubes are made of same sized nanocrystals of $16 \mathrm{~nm}$, the specific surface area can be calculated to be $63.6 \mathrm{~m}^{2} / \mathrm{g}$, slightly smaller than but very close to the BET result, $74.3 \mathrm{~m}^{2} / \mathrm{g}$. Such a small 
difference can be easily explained by considering the fact that the cubic nanocrystals have some facets partially overlapped when the mesocrystals are formed through homoepitaxial aggregation of nanocrystals. The differences in carbon content and BET surface area obtained from calculation and measurements are indicative that the carbon coating has a porous nature as commonly reported in literature ${ }^{[28,29]}$. The valence state of Mn ions in resulting sample was analyzed using X-ray photoelectron spectroscopy (XPS) (Figure 1f) and the separation of $11.6 \mathrm{eV}$ between $\mathrm{Mn} 2 \mathrm{p}_{1 / 2}$ and $\mathrm{Mn} 2 \mathrm{p}_{3 / 2}$ agrees with the characteristic of $\mathrm{MnO}^{[30,31]}$, implying that the phase analyses from XRD is reasonable above. The $\mathrm{Mn} 2 \mathrm{p}_{3 / 2}$ peak can be fitted by three Gaussian functions and the simulative peaks are located at $640.8,641.8$ and $644.2 \mathrm{eV}$, respectively. The peak at $642.2 \mathrm{eV}$ derives from $\mathrm{Mn}^{3+}$ ions and the other two peaks corresponds to $\mathrm{Mn}^{2+}$ ions ${ }^{[32,33]}$. The content $\mathrm{Mn}^{3+}$ ions was estimated through utilizing the intensities from the simulative peaks area and found to be $11.8 \%$ which implied the $\mathrm{Mn}^{7+}$ reduced to $\mathrm{Mn}^{2+}$ incompletely and suggested the cationic vacancies could be created in the $\mathrm{MnO}$ lattice for charge balance in the nanocrystals.

When no stabilization mechanisms such as electrostatic double layer stabilization and polymeric layer steric stabilization, nanocrystals would aggregate to form microspheres in order to minimize the total energy ${ }^{[34]}$, except for using hard template $^{[35]}$ or crystallographic orientation of nanocrystal ${ }^{[36]}$ to form cubic shapes. Although the exact formation mechanism of mesocrystal $\mathrm{MnO}-\mathrm{C}$ cubes need further studies, the surface energy of crystal facets and the effect of PVA molecular can 
provide a clue to explain the process of the formation of mesocrystal $\mathrm{MnO}-\mathrm{C}$ cubes as illustrated in Figure 2. After initial nucleation, the subsequent growth would have different advancement rates along different crystal orientations being directly dependent on the surface energy of corresponding crystal planes/facets. From the lattice parameter $(a)$, coordination number $(\rho)$, and bonding strength $(\delta)$ of Mn-O bond, the surface energy of $\{100\},\{110\}$ and $\{111\}$ facets can be calculated; the values are $\Upsilon_{\{100\}}=4 \delta / a^{2}<\Upsilon_{\{110\}}=4.24 \delta / a^{2}<<\Upsilon_{\{111\}}=10.39 \delta / a^{2}[37,38]$. Therefore, $\mathrm{MnO}$ nuclei would have preferential growth along <111> directions, leading to a thermodynamic equilibrium crystal shape of cubes surrounded with the lowest surface energy $\{100\}$ facets; similar results have been widely reported in literature such as $\mathrm{Cu}_{2} \mathrm{O}^{[39]}$. In the growth process of initial/primary nanocrystals, macromolecular PVA, with a degree of polymerization of $1750 \pm 50$, disperses into the clearances of nanocrystals and would hinder the diffusion of the nanocrystals, allowing their attachment and assembly into ordered aggregates (mesocrystals) to lower the total energy ${ }^{[23,24,40]}$. The structure-directing effect of organic additives benefits to drive the mesoscopic subunits assembled regularly has been verified in pervious literature ${ }^{[24,}$ 41]. Thus, the nanocrystal cubes would homoepitaxially aggregate rather than the classic atom-by-atom growth in the initial process because the initial adhesion force or energy is not too big that the nanocrystal cubes have sufficient time and freedom to align up epitaxially before irreversibly bounded together ${ }^{[22]}$. Not only does PVA assist the ordering of nanocrystals, but also help to produce mesopores in the assembled aggregates as the reported effect in the synthesis zeolites ${ }^{[37]}$. As a result, the bounded 
nanocrystals show as a cubic shape and contain an amount of voids which exhibit as the surface area or mesopore channels. The PVA chains could also be pyrolyzed and converted to porous carbon coating covered on the surface of $\mathrm{MnO}$ nanocrystals as verified by the results from BET and TG mentioned above. This porous carbon coating benefits the penetration of electrolyte and charge transfer for enhancing the electrochemical kinetics in the energy storage reaction ${ }^{[24,42]}$.
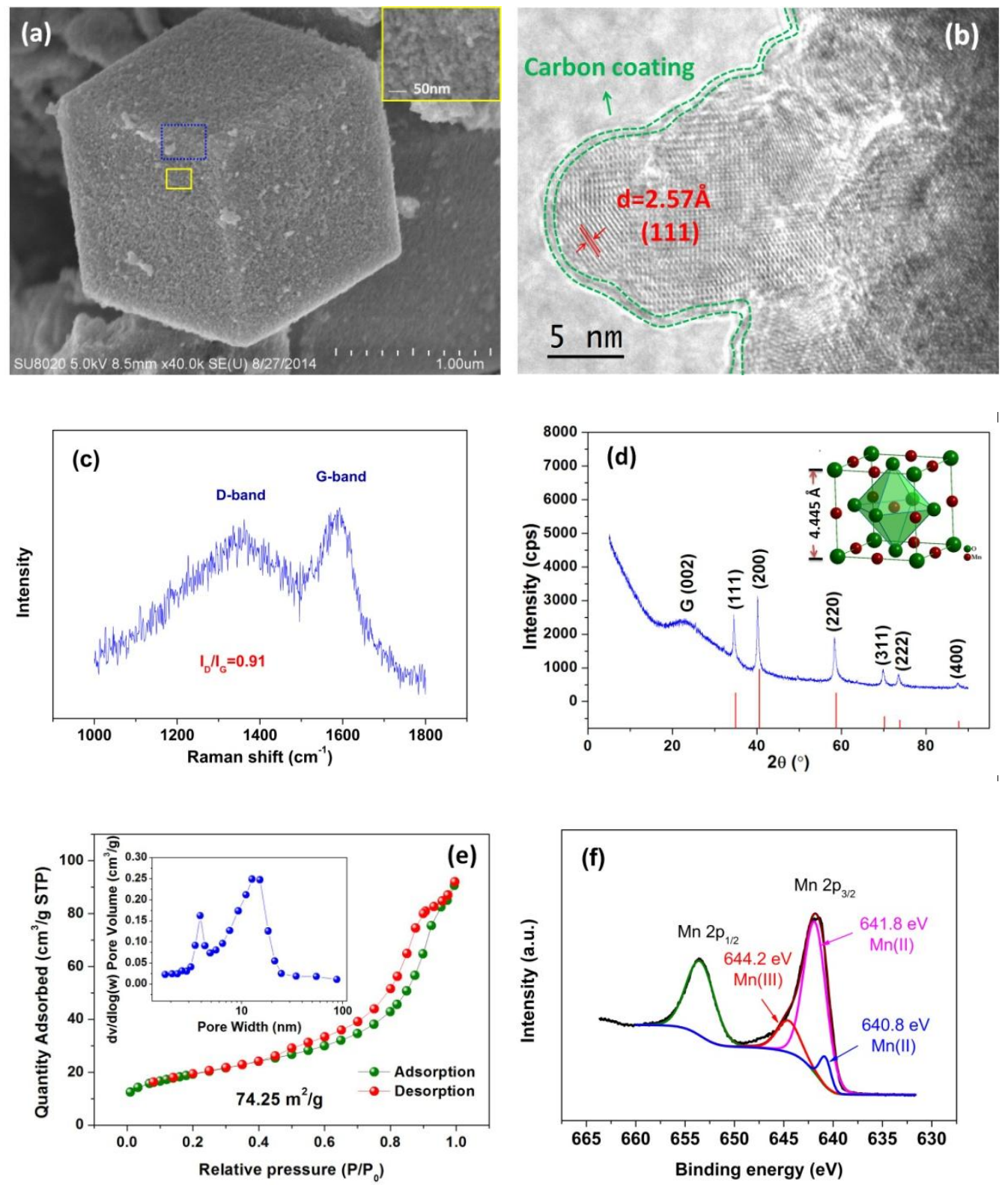
Figure 1. (a) SEM photo of MnO from PVA assisted hydrothermal method with a cubic shape. (b) HRTEM image of nanocrystals and a carbon coating deposited on their surface. The fringe spacing marked by red arrows relates to the planar distance of (111) in MnO. (c) Raman spectrum of the sample and the intensity ratio of $\mathrm{D}$ and $\mathrm{G}$ bands indicates a considerable degree of graphitization. (d) XRD pattern of sample. Except for the characteristic peaks from $\mathrm{MnO}$, the broad peak at $26^{\circ}$ agrees with graphite character and verifies the high degree of graphitization of carbon as shown in Raman spectrum. (e) Nitrogen sorption curves and pore size distribution of the sample. (f) XPS spectrum of mesocrystal $\mathrm{MnO}$. The fitted $\mathrm{Mn} 2 \mathrm{p}_{3 / 2}$ contains three simulative peaks located at 640.8 , 641.8 and $644.2 \mathrm{eV}$, respectively. The peak at $642.2 \mathrm{eV}$ derives from $\mathrm{Mn}^{3+}$ ions and the other two peaks correspond to $\mathrm{Mn}^{2+}$ ions.

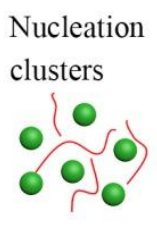

Preferentia growth

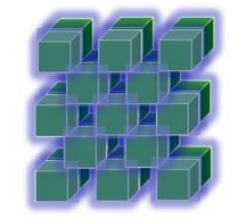

Carbon coated

mesocrystal $\mathrm{MnO}$ cube

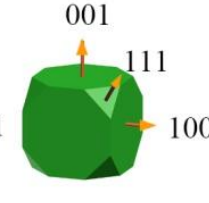

Completed
growth

Homoepitaxial

connection

Primary

nanocrystals
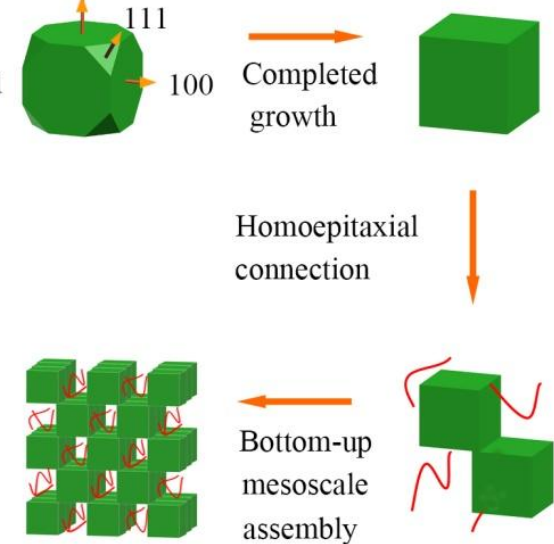

Precursor of

mesocrystal $\mathrm{MnO}$ cube

Figure 2. Schematic illustration of the formation process of mesocrystal $\mathrm{MnO}$ cube. $\mathrm{MnO}$ nuclei favor the preferential crystal growth along <111> directions to form a nanocube. PVA hinders the diffusion of the nanocrystals, allowing their attachment and assembly into ordered aggregates with a certain porosity ${ }^{[22,43]}$. Finally, PVA is pyrolyzed during the heating treatment to form a porous carbon coating on the surface of nanocrystals.

Electrochemical properties of $\mathrm{MnO}-\mathrm{C}$ were characterized and specific capacities were calculated on the total mass of materials containing $\mathrm{MnO}$ core and porous carbon coating. Cyclic voltammograms (CV) was tested for 3 cycles at a sweep rate of 0.1 
$\mathrm{mV} / \mathrm{s}$ in the potential range from 0.01 to $3.0 \mathrm{~V} v s \mathrm{Li} / \mathrm{Li}^{+}$at room temperature and the measured CV curves are shown in Figure 3a. In the first cathodic scan, weak peaks located at $0.5-2.2 \mathrm{~V}$, which disappear in the following cycles, correspond to the formation of a solid electrolyte interphase (SEI) film due to the decomposition of the electrolyte on the $\mathrm{MnO}$ surface. In addition, the strong peak appeared at $0.3 \mathrm{~V}$ relates to the decomposition of $\mathrm{MnO}$ into $\mathrm{Mn}$ and $\mathrm{Li}_{2} \mathrm{O}$. Upon charge, one peak appears at 1.22 $\mathrm{V}$ in the anodic scan, which can be assigned to the oxidation of $\mathrm{Mn}$ and decomposition of $\mathrm{Li}_{2} \mathrm{O}$. All characteristics agree with the reported $\mathrm{MnO}$ anodes ${ }^{[30,42 \text {, }}$ ${ }^{44]}$. Moreover, the curve in the third scan is similar to that of the second one, implying that $\mathrm{MnO}-\mathrm{C}$ has a highly reversible property. Noteworthy, $\mathrm{MnO}$ stores chemical energy through conversion reaction ${ }^{[42]}$ :

$$
\mathrm{MnO}+2 \mathrm{Li}^{+}+2 \mathrm{e}^{-} \rightarrow \mathrm{Mn}+\mathrm{Li}_{2} \mathrm{O}
$$

with a theoretical capacity of $760 \mathrm{~mA} / \mathrm{g}$ in $\mathrm{Li}$ ion system. The rate capability of MnO-C (Figure 3b) was also tested with various current densities in the potential range of $0.05-2.5 \mathrm{~V}$ in a $\mathrm{Li}$ ion half-cell where lithium metal was used as the counter electrode. The initial discharge capacity of MnO-C reaches up to $1196 \mathrm{mAh} / \mathrm{g}$ at a current density of $0.1 \mathrm{~A} / \mathrm{g}$, but the first charge capacity is $629 \mathrm{mAh} / \mathrm{g}$ and the subsequent discharge capacity reduces to $637 \mathrm{mAh} / \mathrm{g}$ in the second cycle. The distinct difference between the initial discharge and charge implies the formation of solid electrolyte interphase (SEI) film exhausted Li ions in this process ${ }^{[45]}$. Although the formation and composition of SEI are complex, the excess exhaustion of $\mathrm{Li}$ ions for conversion reaction mainly attribute to the formation of SEI from side interfacial 
reaction between electrode and electrolyte in the discharge process of $\mathrm{MnO}-\mathrm{C}^{[46,47]}$. This phenomenon agrees with the change of cathodic peaks in the first and second scans. The thickness of SEI can be estimated from the exhausted Li ions and the surface area of sample, and the value is around $4 \mathrm{~nm}$. The SEI film and carbon coating are stabilizers to inhibit the crack or collapse of MnO-C structure ${ }^{[48]}$. In general, conversion reaction accompanies with a relatively large volume change of active particles, and the local stress concentration from phase transition could induce the particles crack that accelerates the degradation of electrode ${ }^{[48]}$. Porous carbon coating and contractile SEI film as the buffering protection net bind the mesocrystal $\mathrm{MnO}$ to limit the side effect from volume change. Besides, the smaller size of nanocrystals can also avoid the stress concentration in the discharge process. Although the SEI film has a complex composition, the positive effects are considered as the descriptions. Thus, the exhausted $\mathrm{Li}$ ions are deserved for $\mathrm{MnO}-\mathrm{C}$ electrode in the first cycle. Furthermore, in rate performance tests, the electrode was tested at various current densities from 0.1 to $2 \mathrm{~A} / \mathrm{g}$, it displayed discharge capacities of 637, 473, 352, 261 and $183 \mathrm{mAh} / \mathrm{g}$, respectively. More importantly, the capacity retained $515 \mathrm{mAh} / \mathrm{g}$ when the current density returned to $0.1 \mathrm{~A} / \mathrm{g}$, which is higher than the reported capacity of the yolk-shell $\mathrm{MnO}$ nanorods of $474 \mathrm{mAh} / \mathrm{g}$ (tested in a much large voltage window of 0.01-3.0 V) ${ }^{[42]}$. Meanwhile, a solid micro-sized cubic MnO (labeled as Microsized $\mathrm{MnO}$ ) was also tested with the same conditions for contrasting electrochemical performance. The morphology and phase of this contrasting sample are exhibited in Figure S3. Microsized MnO mesocrystals delivered the discharge capacities of 326, 
$188,125,77$ and $39 \mathrm{mAh} / \mathrm{g}$ at $0.1,0.2,0.5,1$ and $2 \mathrm{~A} / \mathrm{g}$, respectively, and the retaining specific capacity was $238 \mathrm{mAh} / \mathrm{g}$ at $0.1 \mathrm{~A} / \mathrm{g}$ after the high rate tests (Figure $3 \mathrm{~b}$ ). These values are less competitive than those of $\mathrm{MnO}-\mathrm{C}$ at any discharge current densities, manifesting the unique microstructure endows the superior performances to $\mathrm{MnO}-\mathrm{C}$. The high capacities can be attributed to four aspects: firstly, the smaller nanocrystals in $\mathrm{MnO}-\mathrm{C}$ mesocrystals possess the larger surface are and higher reactive activity that enhanced the reversibility of conversion reaction, at the same time these smaller nanocrystals shorten the distance of ions diffusion to improve the rate capability of electrode material; Secondly, the homoepitaxial aggregation of nanocrystals ensures better transport properties between adjacent nanocrystals and throughout the entire electrodes. Thirdly, the porous carbon coating not only provide the penetration channels for electrolyte, but also guarantee the fast charge transfer in the electrode reaction. And lastly, the mesopores in $\mathrm{MnO}-\mathrm{C}$ benefit the exchange of mass in electrode and electrolyte in the whole half-cell system, and the SEI film on the particles surface hinders the stress destroy during the cycles. The synergistic effect was also found and reported in other nanostructured electrode materials with carbon coating $^{[19,44]}$. Electrochemical impedance spectroscopy (EIS) as an effective approach was employed to investigate the electrochemical characteristics of electrode materials, and Figure $3 \mathrm{c}$ compares the impedance spectra of $\mathrm{MnO}-\mathrm{C}$ and Microsized $\mathrm{MnO}$. The inset exhibits the equivalent circuit, where $R_{s}, R_{f}, R_{c t}, C P E$ and $Z_{W}$ represent the resistance of the electrolyte, the resistance of the SEI film and charge transfer resistance, the double layer capacitance and the Warburg resistance, respectively. All 
the curves display a semicircle in the high frequencies and followed by a straight line in the low frequencies. The arcs in high frequencies are assigned to the charge transfer resistance of electrode materials ${ }^{[42]}$. Remarkably, the value of MnO-C sample (93 $\Omega$ ) is smaller than half of that of Microsized $\mathrm{MnO}(191 \Omega)$, indicative of the excellent conductivity in the MnO-C as described above. In addition, $\mathrm{Li}$ ion diffusion coefficient of samples also can be calculated from the low frequencies plots of EIS spectra (Figure 3d) based on the following equations ${ }^{[49]}$.

$$
\begin{gathered}
\mathrm{Z}^{\prime}=\mathrm{R}_{\mathrm{s}}+\mathrm{R}_{\mathrm{f}}+\mathrm{R}_{\mathrm{ct}}+\sigma_{\mathrm{w}} \omega^{-1 / 2} \\
\mathrm{D}_{\mathrm{Li}^{+}}=\frac{\mathrm{R}^{2} \mathrm{~T}^{2}}{2 \mathrm{~A}^{2} \mathrm{n}^{4} \mathrm{~F}^{4} \mathrm{C}^{2} \sigma_{\mathrm{w}}^{2}}
\end{gathered}
$$

where $\omega, \mathrm{A}, \mathrm{n}, \mathrm{F}, \mathrm{C}, \mathrm{R}$ and $\mathrm{T}$ stands for the angular frequencies, electrode area, electrons number, Faraday constant and the molar concentration of $\mathrm{Li}$ ions, respectively. The calculated $\mathrm{Li}$ ion diffusion coefficients of $\mathrm{MnO}-\mathrm{C}$ and microsized $\mathrm{MnO}$ are $3.33 \times 10^{-13} \mathrm{~cm}^{2} / \mathrm{s}$ and $6.96 \times 10^{-14} \mathrm{~cm}^{2} / \mathrm{s}$, respectively. The enhanced ionic conductivity in $\mathrm{MnO}-\mathrm{C}$ derives from two reasons, one originates from the shortened distance of ions diffusion due to the small size of nanocrystals, the other stems from the defects, cationic vacancies, created in the synthesis process because the high valence state of $\mathrm{Mn}^{3+}$ resided into the $\mathrm{MnO}$ lattice. XPS analysis above verified the existence of cationic vacancies that leave more open void space for easy lithium ion diffusion $^{[49-51]}$. In addition, electrical conductivities of $\mathrm{MnO}-\mathrm{C}$ and microsized $\mathrm{MnO}$ measured through direct current (DC) four probe technique are $2.97 \times 10^{-5} \mathrm{~S} / \mathrm{cm}$ and $<10^{-6} \mathrm{~S} / \mathrm{cm}$. The sensitivity of instrument is $10^{-6} \mathrm{~S} / \mathrm{cm}$ so that the electrical conductivity of microsized $\mathrm{MnO}$ was not measured accurately. Thus, it is believed 
that microsized $\mathrm{MnO}$ has an electrical conductivity of $<10^{-6} \mathrm{~S} / \mathrm{cm}$. Combining with the Raman analysis, the thin carbon coating with high degree of graphitization contributes to this improved electrical conductivity and the decreased charge transfer resistance in EIS. By these comparisons, mesocrystal $\mathrm{MnO}-\mathrm{C}$ built on carbon coated nanocrystals displays the enhanced electrical conductivity and ionic diffusion coefficient that accelerate the electrochemical reaction in electrode during the process of energy storage. In addition, the cycling stability of $\mathrm{MnO}-\mathrm{C}$ was also tested at $1 \mathrm{~A} / \mathrm{g}$ with 200 cycles and no unperceivable degradation was observed (Figure S4a), at the same time the cycled electrode material was analyzed by SEM and the morphology of mesocrystal cube was not destroyed (Figure S4b), albeit the surface become smooth compared with the pristine sample before cycling (Figure 1a). All these results reveal the $\mathrm{MnO}-\mathrm{C}$ with the excellent microstructural and cycling stability, suggesting that the microstructure, cationic vacancies and porous carbon coating benefit to the electrochemical performances of electrode materials.
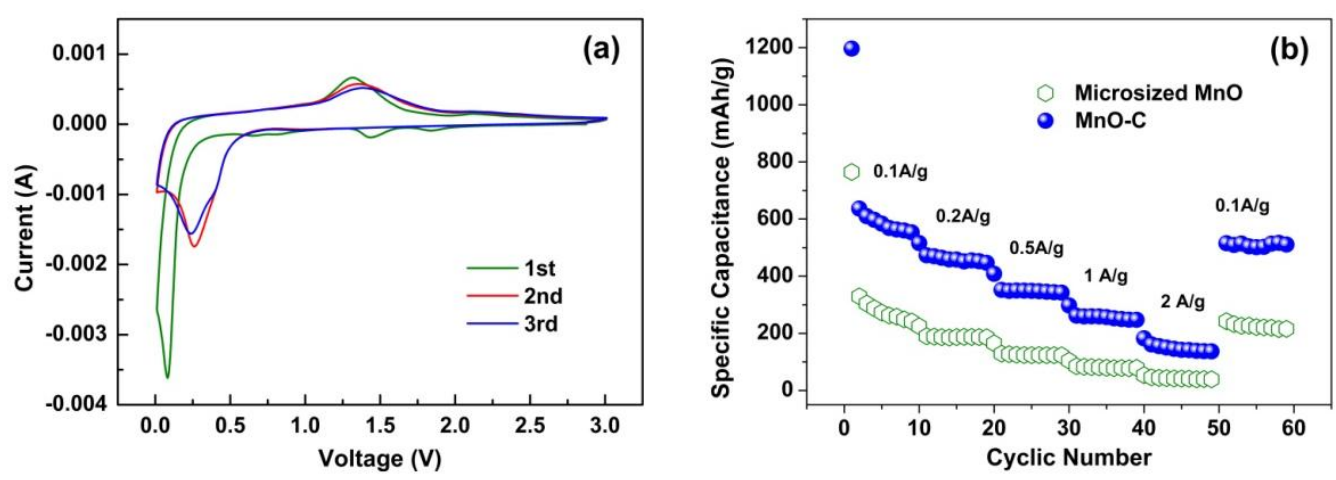

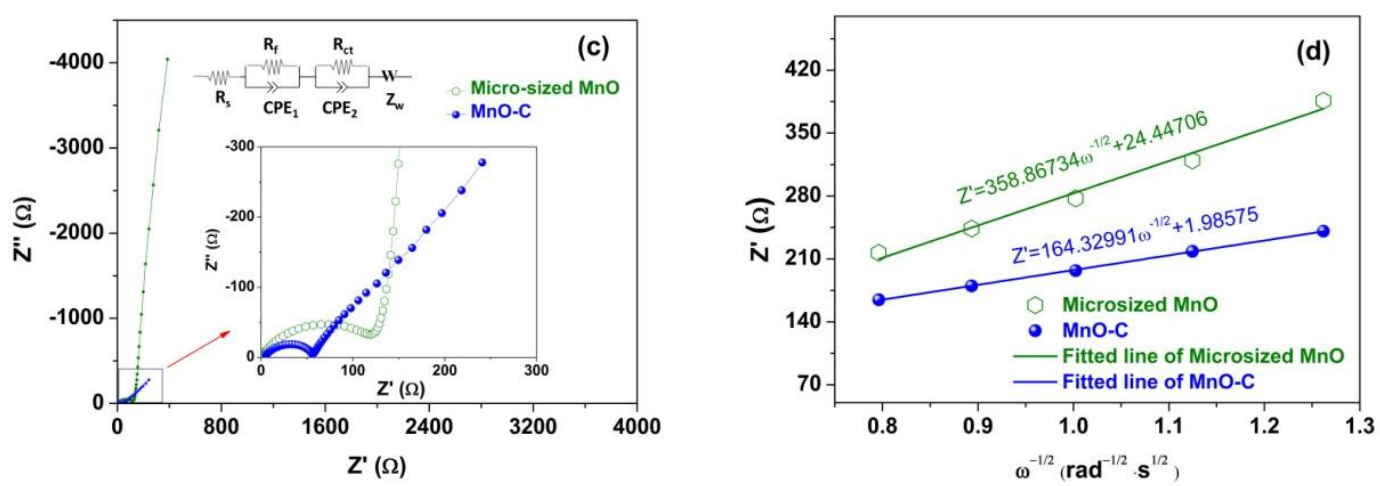

Figure 3. (a) CV curves of mesocrystal $\mathrm{MnO}$ cube. The test were carried out between $0.05-3 \mathrm{~V}$ at $0.1 \mathrm{mV} / \mathrm{s}$. (b) Rate capability of cubic shaped and micro-sized $\mathrm{MnO}$ at various current densities in the voltage window of $0.05-2.5 \mathrm{~V}$. The micro-sized $\mathrm{MnO}$ comes from the commercial $\mathrm{MnO}$ with a micro-sized solid cubic shape. (c) EIS spectra of Microsized $\mathrm{MnO}$ and MnO-C electrode materials in half cells where lithium metal were used as counter electrodes. (d) The relationship between real resistance and frequencies, the slope of the fitting line can be adopted to calculate the Li ion diffusion coefficient.

Based on electrochemical properties of $\mathrm{MnO}-\mathrm{C}$ discussed above, we aim to design a Li-ion capacitor with the MnO-C anode. Thus, the electrochemical nature of $\mathrm{MnO}$ and design rule should be formulated at first. Mn belongs to many-electron atom and the electronic configuration is written as $[\mathrm{Ar}] 3 d^{5} 4 s^{2}$. The overlapping electrons cloud in $3 d$ and $4 s$ orbitals leads to the loss of electrons from $4 s$ at first during the oxidation process, especially for $\mathrm{Mn}$ to $\mathrm{Mn}^{2+}$, the $4 s$ orbital loses two electrons and oxygen anions coordinate with $\mathrm{Mn}^{2+}$ to form $\mathrm{MnO}_{6}$ octahedron that induces the orbital splitting in $3 d$ and form $t_{2 \mathrm{~g}}$ and $e_{\mathrm{g}}$ orbitals with high spin. After splitting, $e_{\mathrm{g}}$ has the higher energy level than that of $4 s$, leading to the electrons in $e_{\mathrm{g}}$ hops into $4 s^{[52]}$. This continuous energy change result to the sloping charge curve in the oxidization. Thus, during the reduction, the incoming electrons jump into $e_{g}$ orbital to decrease the system energy. The same energy level of both $e_{\mathrm{g}}$ orbitals causes the equivalent energy change in the discharge process, displaying a discharge potential plateau ${ }^{[53]}$ (Figure 
S5). The energy difference of electrons hopping in $d$ (or $f$ orbitals) determines the electrochemical potentials of electrode materials ${ }^{[48,54]}$. The electronic structure and available electrovalence of $\mathrm{MnO}$ endows it a valuable discharge voltage plateau $(\sim$ $0.5 \mathrm{~V})$ and high theoretical capacity $(760 \mathrm{mAh} / \mathrm{g})$. These highlights give $\mathrm{MnO}$ a competitive strength as anodes in $\mathrm{Li}$ ion devices. Thus, MnO-C was chosen as anode to design high voltage asymmetric $\mathrm{Li}$ ion capacitor where activated carbon (AC) was used as cathode. The working voltage window of asymmetric supercapacitor can be defined by work functions of electrode materials and the details described by Chang and co-workers ${ }^{[55]}$. Besides, defects from alien atoms can change the surface state that tunes the work function of oxides ${ }^{[56]}$, and difference between the work functions of both electrode mateitrals in asymmetric electrodes opens the wide operation voltage window, similar to battery operation. Based on this principle, operating $\mathrm{MnO}-\mathrm{C}$ anode and $\mathrm{AC}$ cathode in $\mathrm{Li}$ ion electrolyte $\left(1 \mathrm{M} \mathrm{LiPF}_{6}\right.$ in a 1:1:1 (vol \%) mixture of ethylene carbonate, dimethyl carbonate and diethyl carbonate) ensures the capacitor with a wide voltage window. In general, AC works with a electrochemical window within $1 \mathrm{~V}$ in aqueous solution and the achieved energy density is below $10 \mathrm{Wh} / \mathrm{Kg}^{[57]}$. Nonaqueous electrolyte can widen the working window and increase the energy density of $\mathrm{AC}$ in symmetrical capacitor ${ }^{[58]}$. Based on the principles and reported results, we aim to fabricate asymmetric capacitor with $\mathrm{MnO}-\mathrm{C}$ as anode in nonaqueous electrolyte to further increase the energy density of capacitor because $\mathrm{MnO}$ has a low, but safe voltage range of $0.05-2.5 \mathrm{~V}$ vs $\mathrm{Li} / \mathrm{Li}^{+}$and $\mathrm{AC}$ works in 2.0-4.5V vs $\mathrm{Li} / \mathrm{Li}^{+}$in half cells. The difference between the available working 
electrochemical potentials in $\mathrm{MnO}-\mathrm{C}$ and $\mathrm{AC}$ can provides a wide voltage rang of 0.1-4.0V for operating the $\mathrm{MnO}-\mathrm{C} / / \mathrm{AC} \mathrm{Li}$ ion capacitor. Except for ionic liquid as electrolyte to achieve the wide voltage window of $4 \mathrm{~V}^{[12]}$, few reported organic capacitors can operate with a working voltage window of $4 \mathrm{~V}$ (Table S1).

Considering the capacity match between anode and cathode, AC as cathode in half cells were investigated and rate capability is exhibited in Figure S6. The mass ratio was based on the charge balance of both electrodes as follows ${ }^{[55]}$.

$$
\frac{m^{+}}{m^{-}}=\frac{C^{+} \times \Delta E^{+}}{C^{-} \times \Delta E^{-}}
$$

where $C$ is specific capacitance, $\Delta E$ the potential window during the charge/discharge process and $m$ is the mass of the electrode. The mass ratio of MnO-C and AC was calculated to $1: 7.5$ on the electrodes in the asymmetric capacitor. In order to optimize the mass ratio, four sets of $\mathrm{Li}$ ion full capacitor were fabricated and the mass ratio were set at 1:5, 1:6, 1:7 and 1:8. The measured results were shown in Figure 4a and the capacitor with 1:6 mass ratio exhibits the highest capacity. The difference between calculated and measured mass ratio originates from the complex system match in the full capacitor rather than the simple charge equals from electrodes materials. Besides, the charge/discharge curve exhibits the characteristic of supercapacitors as reported ${ }^{[59]}$, implying that the design in this work is reasonable. The rate capability of $\mathrm{MnO}-\mathrm{C} / / \mathrm{AC}$ asymmetric capacitor was tested through galvanostatic charge/discharge under various current densities (Figure 4b). In the first cycle, MnO-C//AC capacitor delivers a considerable capacitance of $270.3 \mathrm{~F} / \mathrm{g}$ at $100 \mathrm{~mA} / \mathrm{g}$ in the working voltage window of 0.1-4.0V. More importantly, the discharge capacitance increases gradually with the 
increase of cycles and the specific capacitance reaches a stable value of $387.7 \mathrm{~F} / \mathrm{g}$ when cycled after 15 th cycles. Two possible mechanisms may explain such an increase in discharge capacitance, one derives from a reversible SEI effect that suggests pseudocapacitive contribution from SEI film during the process of charge and discharge ${ }^{[47,60]}$. The other attributes to initial incomplete penetration of electrolyte in small channels of porous carbon in electrodes, and the penetration accompanied with the activation of $\mathrm{MnO}$ improves as capacitor cycles ${ }^{[61]}$. With current densities ranging from 200 to $8000 \mathrm{~mA} / \mathrm{g}$, the $\mathrm{MnO}-\mathrm{C} / / \mathrm{AC}$ capacitor delivered specific capacitances of $331.8,277.6,233.4,179.5,116.9$ and $51.2 \mathrm{~F} / \mathrm{g}$, respectively. When the current density returned to $100 \mathrm{~mA} / \mathrm{g}$, the specific capacitance retained $372.6 \mathrm{~F} / \mathrm{g}$, indicative of an excellent reversibility. It is worth noting that at a high current density of $8000 \mathrm{~mA} / \mathrm{g}$, the capacitance of $52.1 \mathrm{~F} / \mathrm{g}$ consisted contributions from both conversion reaction of $\mathrm{MnO}$ nanocrystals and surface ions sorption. Generally, the maximum specific double layer capacitance is $\sim 8.5 \mu \mathrm{F} / \mathrm{cm}^{2}$ in carbonaceous materials using non-aqueous electrolyte ${ }^{[62]}$, thus the specific capacity should be $7.0 \mathrm{~F} / \mathrm{g}$ from surface ions sorption in $\mathrm{MnO}-\mathrm{C}$, implying that conversion reaction from $\mathrm{MnO}$ also play an important role in the capacitor when the current density reaches up to 8000 $\mathrm{mA} / \mathrm{g}$. In order to contrast the performance of $\mathrm{MnO}-\mathrm{C}$ anode in asymmetric capacitor, a symmetric Li ion capacitor was fabricated on $\mathrm{AC}$ electrodes (marked as AC//AC capacitor) and the rate capability was also tested as shown in Figure 4c. It is worth noting that this $\mathrm{AC} / / \mathrm{AC}$ capacitor also can operate in a voltage window of $0.1-4.0 \mathrm{~V}$. However, the electrochemical basic differs from that of MnO-C//AC capacitor. AC 
has a superior chemical stability in organic electrolyte, and stores charge through ions sorption/desorption on the surface. Thus, the working voltage window of AC//AC capacitor depends on the decomposition limits of electrolyte. The similar trend of specific capacitance occurs in the first 30 cycles and the profiles of charge/discharge curves display the EDLC characters. However, AC//AC capacitor only delivers the specific capacity of $49.6 \mathrm{~F} / \mathrm{g}$ at $100 \mathrm{~mA} / \mathrm{g}$. As the current density increases to 8000 $\mathrm{mA} / \mathrm{g}$, the specific capacitance retains $12.2 \mathrm{~F} / \mathrm{g}$, which is far below that of MnO-C//AC capacitor. Comparing the charge/discharge times at same current densities can also find the $\mathrm{MnO}-\mathrm{C} / / \mathrm{AC}$ capacitor with the superiority. Figure $4 \mathrm{~d}$ shows the beginning discharge voltages at various current densities and the voltages present linear relation, indicating the internal resistances are constant with the increase of cycles and current densities, and no side reactions occurred to deteriorate the charge transfer resistances between the electrodes and electrolyte. The slopes of lines reflect the resistance of full capacitors, and the value of MnO-C//AC capacitor is $0.18 \Omega \mathrm{g}$ which is smaller than that of AC//AC capacitor of $0.32 \Omega \mathrm{g}$, manifesting that $\mathrm{MnO} / / \mathrm{AC}$ system with an excellent pathway for electrons transfer as characterized by DC direct probe method and EIS in half cells. EIS spectra of full capacitors (shown in Figure S7) display the $\mathrm{MnO}-\mathrm{C} / / \mathrm{AC}$ and $\mathrm{AC} / / \mathrm{AC}$ with the internal resistances of 0.21 and $0.11 \Omega \mathrm{g}$, respectively. Although the values are different with those from IR drop in Figure 4d, the trend is in accord with the results in IR drops. This resistance difference between IR drops and EIS may derive from the polarization effect, because the IR drops obtained from a dynamic state in the galvanostatic process that must 
induce the polarization resistance, but the EIS measured at the static state of capacitors and the polarization resistance can be avoided. In order to contrast the performance of full capacitors, the energy and power density of $\mathrm{MnO}-\mathrm{C} / / \mathrm{AC}$ capacitor was calculated as shown in Figure 4e, the achieved maximum energy and power density in $\mathrm{MnO}-\mathrm{C} / / \mathrm{AC}$ full capacitor can reach up to $227 \mathrm{Wh} \mathrm{kg}^{-1}$ and $2952 \mathrm{~W} / \mathrm{Kg}$, respectively, and the reported $\mathrm{Li}$ ion capacitors built on different materials are also displayed in the plot for comparison. The $\mathrm{MnO}-\mathrm{C} / / \mathrm{AC}$ capacitor exhibits the competitive strength in the energy and power densities, and at a certain extent, it bridges the gap between conventional batteries and supercapacitors ${ }^{[63]}$. In addition, cycling stability of $\mathrm{MnO}-\mathrm{C} / / \mathrm{AC}$ capacitor was tested at $4000 \mathrm{~mA} / \mathrm{g}$ and $92.5 \%$ capacitance retains after 3500 cycles (Figure 4f), the degradation rate is only $0.002 \%$ per cycle that indicates the $\mathrm{MnO}-\mathrm{C} / / \mathrm{AC}$ capacitor with a higher cycling stability compared with the reported literatures as highlighted in Figure S8. For example, $\mathrm{H}_{2} \mathrm{Ti}_{2} \mathrm{O}_{13} / / \mathrm{CMK}-3 \mathrm{Li}$ ion capacitor cycled at $1.5 \mathrm{~A} / \mathrm{g}$ within the voltage window of $0-3.5 \mathrm{~V}$, the capacitance retained $80 \%$ after 1000 cycles with a degradation rate of $0.02 \%$ per cycle ${ }^{[64]}$. MnO@CNS//CNS capacitor operated at 5A/g in the voltage range of $1.0-4.0 \mathrm{~V}$ and capacitance retention is $76 \%$ after 5000 cycles with a degradation rate of $0.005 \%$ per cycle. The MnO-C//AC capacitor in this work demonstrated higher energy and power density with excellent cycling stability synchronously due to the fast charge/ion transfer and the shortened distance for ion diffusion in $\mathrm{MnO}-\mathrm{C}$ electrode, and the high operating voltage in the full capacitor, with a promising market potential in the nonaqueous asymmetric capacitors for powering electric 
vehicles or portable electronic devices in the future.
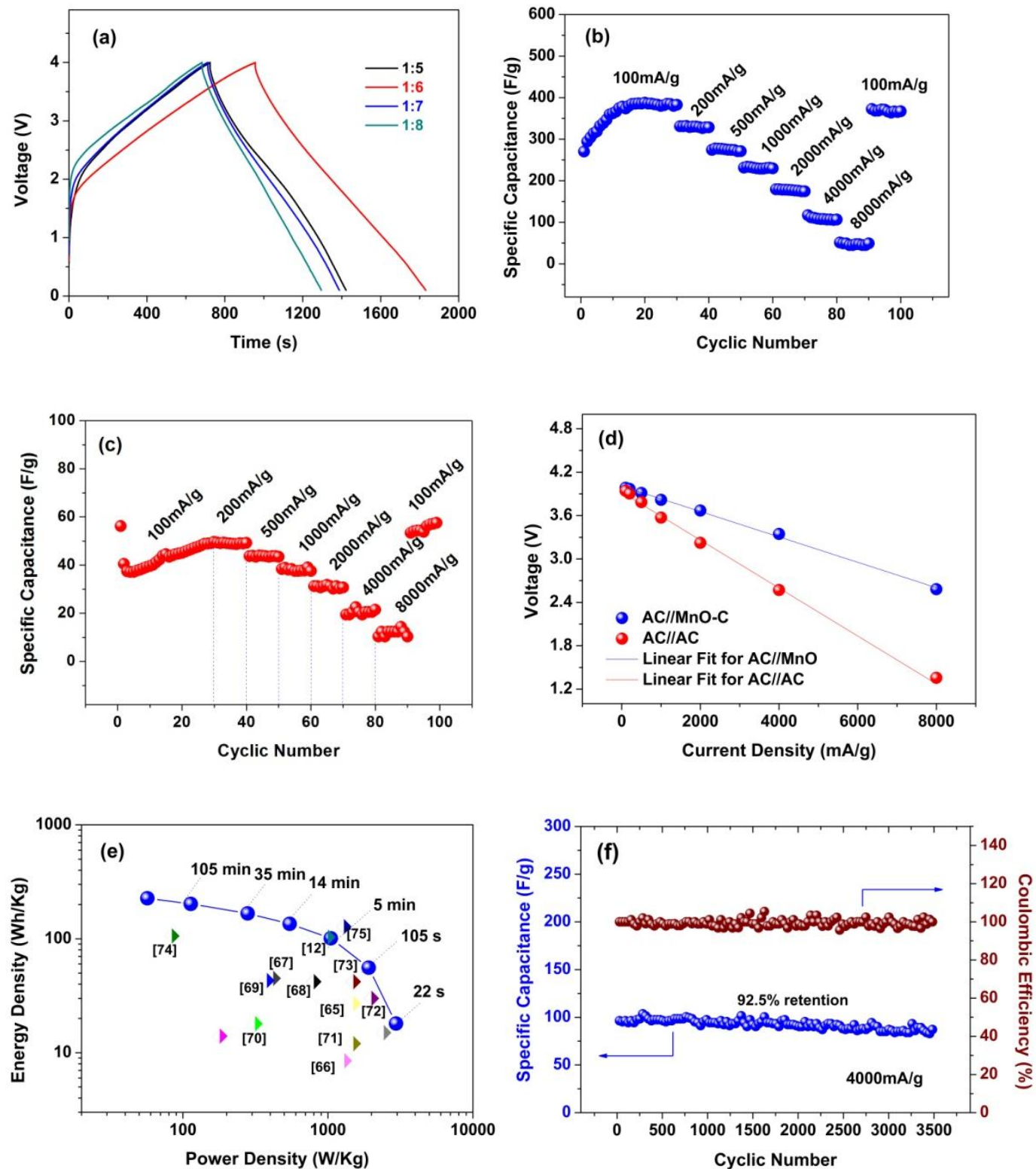

Figure 4. (a) Profile of charge/discharge curves of full capacitors with different mass ratio in cathodes and anodes. The measurement based on the total mass of two electrodes. (b) Rate capability $\mathrm{AC} / \mathrm{MnO}-\mathrm{C}$ capacitor at various current densities in the voltage range of 0.1-4.0V. (c) Rate capability of AC//AC capacitor at various current densities in the voltage range of 0.1-4.0V. The specific capacitances in (b) and (c) are calculated on the mass of active materials in the anodes. (d) The capacitor voltages at the beginning of discharge under different current densities. Not only do the slopes of the fitting lines demonstrate the internal resistances of capacitors and the electrical conductivities electrode materials, but also the associations are linear in the points, indicating that no side reactions occurred to increase the internal resistances in the process of 
charge/discharge. (e) Ragone Plot of MnO-C//AC capacitor and the color points display reported literatures. As defined for pseudo-capacitive materials, the time domain from 10s to $10 \mathrm{~min}$ represents the materials with an excellent rate performance in capacitors ${ }^{[62]}$. (g) The cycling performance of $\mathrm{MnO}-\mathrm{C} / / \mathrm{AC}$ capacitor after test of rate capability and the gradation is $0.002 \%$ per cycle at $4000 \mathrm{~mA} / \mathrm{g}$.

\section{Conclusions}

Mesocrystal $\mathrm{MnO}$ cubes consisting of homoepitaxially aggregated $\mathrm{MnO}$ nanocrystals with percolated porous channels were synthesized through PVA assisted hydrothermal method in one step. PVA additive not only assisted the assembly of MnO nanocrystals, but also provides carbon source to build electron highway for charge transfer $(2.97 \times$ $10^{-5} \mathrm{~S} / \mathrm{cm}$ ) in electrochemical reaction. Besides, the mesopores in the mesocrystal cubes supply channels for penetration of electrolyte and enhance the contacting area between electrode materials and electrolyte. The nanocrystals shorten ionic diffusion distance and the cationic vacancies provide void space for fast ion migration $\left(3.33 \times 10^{-13} \mathrm{~cm}^{2} / \mathrm{s}\right)$, thus the resulting sample displays the enhanced discharge capacity of $637 \mathrm{mAh} / \mathrm{g}$ and improved rate capability in half cells. In addition, the electronic structure of $\mathrm{Mn}$ ions determines the charge/ discharge characteristic of $\mathrm{MnO}$ and the relationship between electrochemical potentials of electrode materials provides a rule to design asymmetric capacitors with an expected voltage window. A $4 \mathrm{~V}$ high voltage $\mathrm{Li}$ ion capacitor was fabricated on meoscrystal $\mathrm{MnO}$ as anode and activated carbon cathode, and displayed the maximum high energy of $227 \mathrm{Wh} / \mathrm{Kg}$ and power density of $2952 \mathrm{~W} / \mathrm{Kg}$ with the excellent cycling stability synchronously. We believe that such low-cost, high-performance three dimensional mesopore framework $\mathrm{MnO}$ using earth abundant and environmentally friendly element can offer great promise in energy 
storage device applications.

\section{Author information}

\section{Corresponding Author}

*E-mail: gzcao@u.washington.edu

\section{Acknowledgments}

This work was partly supported by the "Thousands Talents" program for the pioneer researcher and his innovation team, China and also by the National Science Foundation (NSF, DMR 1505942). This work was also supported by the National Science Foundation of China (51374029), Program for New Century Excellent Talents in University (NCET-13-0668), and China Postdoctoral Science Foundation (2015M570987).

\section{References}

[1] Dunn, B.; Kamath, H.; Tarascon, J.-M. Science 2011, 334, 928-935.

[2] Tarascon;, J.-M.; Simon, P. Electrochemical Energy Storage. John Wiley \& Sons, Inc: 2015.

[3] Zhang, Q. F.; Uchaker, E.; Candelaria, S. L.; Cao, G. Z. Chem. Soc. Rev. 2013, 42, 3127-3171.

[4] Liu, C.; Neale, Z. G.; Cao, G. Mater Today 2015. DOI:10.1016/j.mattod.2015.10.009

[5] Massé, R.; Uchaker, E.; Cao, G. Sci. China Mater. 2015, 58, 715-766.

[6] Aravindan, V.; Gnanaraj, J.; Lee, Y.-S.; Madhavi, S. Chem.Rev. 2014, 23, 11619-11635.

[7] Simon, P.; Gogotsi, Y.; Dunn, B. Science 2014, 343, 1210-1211.

[8] Dubal, D. P.; Ayyad, O.; Ruiz, V.; Gomez-Romero, P. Chem. Soc. Rev. 2015, 44, 1777-1790.

[9] Zhang, L. L.; Zhao, X. S. Chem. Soc. Rev. 2009, 38, 2520-2531.

[10] Candelaria, S. L.; Garcia, B. B.; Liu, D. W.; Cao, G. Z. J. Mater. Chem. 2012, 22, 9884-9889.

[11] Aurbach, D.; Talyosef, Y.; Markovsky, B.; Markevich, E.; Zinigrad, E.; Asraf, L.; Gnanaraj, J. S.; Kim, H.-J. Electrochim. Acta 2004, 50, 247-254.

[12] Cui, C. J.; Qian, W. Z.; Yu, Y. T.; Kong, C. Y.; Yu, B.; Xiang, L.; Wei, F. J. Am. Chem. Soc. 2014, 136, 2256-2259. 
[13] Abouimrane, A.; Belharouak, I.; Amine, K. Electrochem. Commun. 2009, 11, 1073-1076.

[14] Aurbach D, G. Y., Dekker M. Nonaqueous electrochemistry. CRC, Boca Raton: 1999.

[15] Goodenough, J. B.; Kim, Y. Chem. Mater. 2010, 22, 587-603.

[16] Wang, Y.; Wang, Y.; Jia, D.; Peng, Z.; Xia, Y.; Zheng, G. Nano Lett. 2014, 14, 1080-1084.

[17] Chen, W.; Rakhi, R. B.; Hu, L. B.; Xie, X.; Cui, Y.; Alshareef, H. N. Nano Lett. 2011, 11, 5165-5172.

[18] Liu, C.; Song, H.; Zhang, C.; Liu, Y.; Zhang, C.; Nan, X.; Cao, G.. Nano Res. 2015, 8, 3372-3383.

[19] Jiang, H.; Hu, Y. J.; Guo, S. J.; Yan, C. Y.; Lee, P. S.; Li, C. Z. ACS Nano 2014, 8, 6038-6046.

[20] Zhang, S.; Zhu, L.; Song, H.; Chen, X.; Zhou, J. Nano Energy 2014, 10, 172-180.

[21] Bruce, P. G.; Scrosati, B.; Tarascon, J.-M. Angew. Chem. Int. Edit 2008, 47, 2930-2946.

[22] Uchaker, E.; Cao, G. Nano Today 2014, 9, 499-524.

[23 Wei, X.; Xu, G.; Ren, Z.; Xu, C.; Shen, G.; Han, G. J. Am. Chem. Soc.2008, 91, 3795-3799.

[24] Gong, J.-Y.; Yu, S.-H.; Qian, H.-S.; Luo, L.-B.; Li, T.-W. J Phys. Chem. C 2007, 111, 2490-2496.

[25] Zhou, Y.; Candelaria, S. L.; Liu, Q.; Uchaker, E.; Cao, G. Nano Energy 2015, 12, 567-577.

[26] Pimenta, M. A.; Dresselhaus, G.; Dresselhaus, M. S.; Cancado, L. G.; Jorio, A.; Saito, R. Phys. Chem. Chem. Phys. 2007, 9, 1276-1290.

[27] Li, Z. Q.; Lu, C. J.; Xia, Z. P.; Zhou, Y.; Luo, Z. Carbon 2007, 45, 1686-1695.

[28] Shen, L. F.; Li, H. S.; Uchaker, E.; Zhang, X. G.; Cao, G. Z. Nano Lett. 2012, 12, 5673-5678.

[29] Zhang, C.; Song, H.; Liu, C.; Liu, Y.; Zhang, C.; Nan, X.; Cao, G. Adv. Funct. Mater. 2015, 25, 3497-3504.

[30] Sun, Y.; Hu, X.; Luo, W.; Huang, Y. J. Mater. Chem. 2012, 22, 19190-19195.

[31] Tan, B. J.; Klabunde, K. J.; Sherwood, P. M. A. J. Am. Chem. Soc. 1991, 113, 855-861.

[32] Dong, R.; Ye, Q.; Kuang, L.; Lu, X.; Zhang, Y.; Zhang, X.; Tan, G.; Wen, Y.; Wang, F. ACS Appl. Mater. Inter. 2013, 5, 9508-16.

[33] Di Castro, V.; Polzonetti, G. J. Electron. Spectrosc. Relat. Phenom. 1989, 48, 117-123.

[34] Zhang, L.; Li, N.; Wu, B.; Xu, H.; Wang, L.; Yang, X. Q.; Wu, F. Nano Lett. 2015, 15, 656-661.

[35] Yu, X.-Y.; Wu, H. B.; Yu, L.; Ma, F.-X.; Lou, X. W. Angew. Chem. Int. Edit 2015, 54, 4001-4004.

[36] Sang, W.; Zheng, T.; Wang, Y.; Li, X.; Zhao, X.; Zeng, J.; Hou, J. G. Nano Lett. 2014, 14, 6666-6671.

[37] Cao, G.; Wang, Y. Nanostructures and Nanomaterials: Synthesis, Properties, and Applications. World Scientific Publishing Co Pte Ltd: 2011.

[38] Lalena, J. N.; Cleary, D. A.; Carpenter, E.; Dean, N. F. Inorganic Materials Synthesis and Fabrication. Wiley-Interscience: 2008.

[39] Wang, D.; Mo, M.; Yu, D.; Xu, L.; Li, F.; Qian, Y. Cryst. Growth Des. 2003, 3, 717-720.

[40] Hong, Z.; Wei, M.; Lan, T.; Cao, G. Nano Energy 2012, 1, 466-471.

[41] Wohlrab, S.; Pinna, N.; Antonietti, M.; Cölfen, H. Chemistry - A European Journal 2005, 11, 2903-2913.

[42] Cai, Z.; Xu, L.; Yan, M.; Han, C.; He, L.; Hercule, K. M.; Niu, C.; Yuan, Z.; Xu, W.; Qu, L.; Zhao, K.; Mai, L. 2015, 15, 738-744.

[43] Cölfen, H.; Mann, S. Angew. Chem. Int. Edit 2003, 42, 2350-2365.

[44] Xia, Y.; Xiao, Z.; Dou, X.; Huang, H.; Lu, X. H.; Yan, R. J.; Gan, Y. P.; Zhu, W. J.; Tu, J. P.; Zhang, W. K.; Tao, X. Y. ACS Nano 2013, 7, 7083-7092.

[45] Kohandehghan, A.; Kalisvaart, P.; Kupsta, M.; Zahiri, B.; Amirkhiz, B. S.; Li, Z.; Memarzadeh, E. L.; Bendersky, L. A.; Mitlin, D. J. Mater. Chem.A 2013, 1, 1600-1612. 
[46] Gachot, G.; Grugeon, S.; Armand, M.; Pilard, S.; Guenot, P.; Tarascon, J.-M.; Laruelle, S. J.Power Sources 2008, 178, 409-421.

[47] Ponrouch, A.; Taberna, P.-L.; Simon, P.; Palacín, M. R. Electrochim. Acta 2012, 61, 13-18.

[48] Park, J.-K. Principles and Applications of Lithium Secondary Batteries. Wiley-VCH Germany, 2012.

[49] Song, H.; Liu, Y.; Zhang, C.; Liu, C.; Cao, G. J. Mater. Chem.A 2015, 3, 3547-3558.

[50] Hahn, B. P.; Long, J. W.; Mansour, A. N.; Pettigrew, K. A.; Osofsky, M. S.; Rolison, D. R. Energy Environ. Sci. 2011, 4, 1495.

[51] Liu, D.; Liu, Y.; Garcia, B. B.; Zhang, Q.; Pan, A.; Jeong, Y.-H.; Cao, G. J. Mater. Chem. 2009, 19, 8789-8795.

[52] Zhang, Z. D. Inorganic Chemistry. Press of University of Science and Technology of China 2008.

[53] Yazami, R. Nanomaterials for Lithium-Ion Batteries: Fundamentals and Applications. CRC Press, Taylor \& Francis Group: 2013; pp 227-251.

[54] Islam, M. S.; Fisher, C. A. J. Chem. Soc. Rev. 2014, 43, 185-204.

[55] Chang, J.; Jin, M.; Yao, F.; Kim, T. H.; Le, V. T.; Yue, H.; Gunes, F.; Li, B.; Ghosh, A.; Xie, S.; Lee, Y. H. Adv. Funct. Mater. 2013, 23, 5074-5083.

[56] Kittel, C. Introduction to Solid State Physics (8Th.Edition). Wiley: 2005.

[57] Frackowiak, E. Phys. Chem. Chem. Phys. 2007, 9, 1774-1785.

[58] Zhou, Y.; Candelaria, S. L.; Liu, Q.; Huang, Y.; Uchaker, E.; CaO, G. J. Mater. Chem.A 2014, 2, 8472 .

[59] Wang, H. L.; Xu, Z. W.; Li, Z.; Cui, K.; Ding, J.; Kohandehghan, A.; Tan, X. H.; Zahiri, B.; Olsen, B. C.; Holt, C. M. B.; Mitlin, D. Nano Lett. 2014, 14, 1987-1994.

[60] Laruelle, S.; Grugeon, S.; Poizot, P.; Dollé, M.; Dupont, L.; Tarascon, J.-M. J. Electrochem. Soc. 2002, 149, A627-A634.

[61] Z. Li, J. T. Zhang, Y. M. Chen, J. Li and X. W. Lou, Nat. Commun., 2015, 6. doi:10.1038/ncomms 9850

[62] Conway, B. E. J. Electrochem. Soc. 1991, 138, 1539-1548.

[63] Augustyn, V.; Simon, P.; Dunn, B. Energy Environ. Sci. 2014, 7, 1597-1614.

[64] Wang, Y.; Hong, Z.; Wei, M.; Xia, Y. Adv. Funct. Mater. 2012, 22, 5185-5193.

[65] Wang, X.; Li, G.; Chen, Z.; Augustyn, V.; Ma, X.; Wang, G.; Dunn, B.; Lu, Y. Adv. Energy Mater 2011, 1, 1089-1093.

[66] Wang, Q.; Wen, Z. H.; Li, J. H. Adv. Funct. Mater. 2006, 16, 2141-2146.

[67] Brousse, T.; Marchand, R.; Taberna, P. L.; Simon, P. J.Power Sources 2006, 158, 571-577.

[68] Kim, H.; Cho, M.-Y.; Kim, M.-H.; Park, K.-Y.; Gwon, H.; Lee, Y.; Roh, K. C.; Kang, K. Adv. Energy Mater 2013, 3, 1500-1506.

[69] Wang, D.-W.; Fang, H.-T.; Li, F.; Chen, Z.-G.; Zhong, Q.-S.; Lu, G. Q.; Cheng, H.-M. Adv. Funct. Mater. 2008, 18, 3787-3793.

[70] Aravindan, V.; Cheah, Y. L.; Mak, W. F.; Wee, G.; Chowdari, B. V. R.; Madhavi, S. ChemPlusChem 2012, 77, 570-575.

[71] Jung, H.-G.; Venugopal, N.; Scrosati, B.; Sun, Y.-K. J.Power Sources 2013, 221, 266-271.

[72] Gokhale, R.; Aravindan, V.; Yadav, P.; Jain, S.; Phase, D.; Madhavi, S.; Ogale, S. Carbon 2014, 80, 462-471.

[73] Kaiyappan, K.; Amaresh, S.; Lee, Y. S. ACS Appl. Mater. Inter. 2014, 6, 11357-11367. 
[74] Lee, J. H.; Shin, W. H.; Ryou, M. H.; Jin, J. K.; Kim, J.; Choi, J. W. Chemsuschem 2012, 5, 2328-2333.

[75] R. Yi, S. Chen, J. Song, M. L. Gordin, A. Manivannan and D. Wang, Adv. Funct. Mater., 2014, 24, 7433-7439. 